\title{
DE ONTWIKKELING IN DE FUNCTIE VAN DE OPENBARE ACCOUNTANT IN NEDERLAND
}

\author{
door A. B. Frielink \\ „Iedere Papalagi heeft een beroep. Het is moeilijk \\ nauwkeurig te zeggen, wat dat is". \\ (Erich Scheuermann - De Papalagi).
}

In de beschouwingen over de functie van de openbare accountant in Nederland die de laatste jaren zijn gehouden, hebben een aantal aspecten minder aandacht vermogen te trekken dan zij naar schrijver dezes meent verdienen. In het onderstaande zal getracht worden deze aspecten te belichten.

De groei van de functies van de openbare accountant in Nederland.

Uit de oorspronkelijke, meer comptabele taken van de eerste accountants ontwikkelde zich de functie van onafhankelijke controleur en die van deskundige op het gebied der administratieve organisatie. Ten behoeve van zijn controlerende taak diende de accountant mede kennis te dragen van de handelsusances, de wettelijke regelingen die op het bedrijfsleven kunnen terugslaan en de fiscale voorschriften. Ten behoeve van zijn taak als deskundige op het gebied der administratieve organisatie diende de accountant mede inzicht te hebben in de bedrijfseconomie - dit geldt ook voor de tijd toen deze nog niet als zelfstandige (deel-) wetenschap werd erkend.

De steeds verder gaande complicatie van het bedrijfsleven en de steeds belangrijker wordende belastingen, deden bij het bedrijfsleven de behoefte ontstaan aan adviseurs. De leiders van bedrijven wensten deze adviseurs te raadplegen bij vele gelegenheden waarbij een beslissing moest worden genomen die verstrekkende bedrijfseconomische of fiscale gevolgen kon hebben.

Het is begrijpelijk dat de accountant met zijn kennis van handelsgewoonten, wettelijke bepalingen, bedrijfseconomie en belastingrecht in vele gevallen als een van de belangrijkste adviseurs werd en wordt gezien. Keuze van de accountant als adviseur had en heeft bovendien nog het belangrijke voordeel dat hij als controleur geacht mag worden de betrokken bedrijfshuishouding en de bijzondere omstandigheden daarvan terdege te kennen, waar een andere adviseur zich nieuw zou moeten inwerken. Hieruit groeide de adviserende functie van de accountant.

In de huidige positie worden drie functies onderscheiden:

a. de controleursfunctie;

b. de functie van administratieve deskundige;

c. de adviseursfunctie.

\section{De controleursfunctie.}

In de laatste decenniën is in de literatuur en in de opleiding de nadruk vooral gelegd op de controleursfunctie. Tot op zekere hoogte terecht, want in deze functie treedt de accountant ook buiten de kring van zijn opdrachtgevers. Alleen door deze functie wordt hij vertrouwensman in het maatschappelijk verkeer, naast en behalve zelfstandige uitvoerder van opdrachten ten behoeve van $z$ ijn opdrachtgevers. 
In dit opzicht bestaat er een aanmerkelijk verschil tussen de accountants en de beoefenaren van verscheidene andere vrije beroepen. Deze laatsten aanvaarden opdrachten van bepaalde cliënten en hebben slechts tot taak deze zodanig uit te voeren dat de belangen van die cliënten zo goed mogelijk worden behartigd; zij hebben met name er geen rekening mede te houden welke indruk hun werkzaamheden op buitenstaanders maken. Hiermede wil uiteraard niet gezegd zijn dat de beoefenaren van deze vrije beroepen niet gebonden zouden behoren te zijn aan bepaalde beroeps regels (bij wet of corporatief vastgesteld); deze regels hebben echter een beperkter ratio dan die der accountants. De beroepsregels van vele andere vrije beroepen hebben enerzijds ten doel de opdrachtgevers - die zelf veelal onvoldoende deskundig kunnen zijn - te beschermen tegen onjuist of ondeskundig optreden van de beoefenaar van het vrije beroep, anderzijds het vrije beroep op een bepaald niveau te plaatsen en te handhaven. De beroepsregels der accountants hebben deze zelfde doeleinden, doch bovendien vormen $z$ ij een bescherming van derden die geen opdrachtgevers $z \mathrm{ijn}$, doch wel belanghebbenden, of misschien slechts potentieel-belanghebbenden.

De oorzaak van dit verschil moet niet worden gezocht in de aard van het accountantsberoep als zodanig, doch in de aard van de opdrachten die de accountant ontvangt en de aard van zijn opdrachtgevers. Dit onderscheid van oorzaak lijkt slechts van academische betekenis; praktisch heeft het echter deze consequentie dat de beroepsregels die bescherming van derden beogen niet voor het gehele beroep behoeven te gelden, doch slechts voor die opdrachten en voor die opdrachtgevers waar zich het bijzondere aspect van bescherming van derden voordoet.

$\mathrm{Er}$ is nog een andere reden waarom het juist moet worden geacht dat de controleursfunctie een zeer groot deel van de aandacht verkrijgt. Deze functie maakt thans de kern van het accountantsberoep uit; men kan zich een administratieve deskundige of een adviseur op elk der gebieden waarop het bedrijfsleven adviezen behoeft, voorstellen die geen accountant is; men kan zich echter geen onafhankelijke controleur voorstellen die niet met de naam accountant zou behoren te worden aangeduid. Deze kern kan men niet aantasten, zonder tevens het beroep zelf aan te tasten.

De consequentie hiervan is, dat de openbare accountant onder alle omstandigheden een volslagen controleur zal moeten zijn, dat wil zeggen het controlevak zo volledig zal moeten beheersen als het maar mogelijk moet worden geacht een vak te beheersen. Om het beroep op het thans bereikte niveau te houden is het dus noodzakelijk dat de titel ,accountant" (lid N.I.v.A. of lid V.A.G.A.; straks wellicht „registeraccountant”) alleen wordt gevoerd door degene die een volslagen controleur mag worden genoemd.

Dat voor de volslagen controleur ook te allen tijde kennis van handelsgebruiken, wettelijke voorschriften, fiscale bepalingen en administratieve mogelijkheden, alsmede ervaring noodzakelijk zijn, worde hier slechts terloops opgemerkt; dit behoeft wel geen nader betoog.

\section{De beide andere functies.}

De beide andere functies van de accountant zijn naar hun aard aanzienlijk minder absoluut. Kan men spreken van een volslagen controleur en daaronder verstaan iemand die het controlevak zodanig beheerst dat hij de controleproblemen in hun totaliteit onder de knie heeft, noch van de ad- 
ministratieve deskundige, noch van de adviseur kan een dergelijke absolute qualificatie worden gegeven. De oorzaak van dit onderscheid wordt gevonden in de aard der werkzaamheden:

- de controleur past een bepaalde techniek toe op problemen die in een beperkt aantal categorieën zijn onder te brengen. Deze controletechniek ondergaat uiteraard een evolutie; de toepassing van de op een gegeven ogenblik bestaande techniek betekent echter in feite niets anders dan onderkenning van de categorie waartoe het probleem behoort en een aanpassing van de uit de theorie of de praktijk bekende techniek aan de bijzondere omstandigheden van het concrete probleem. Ter vermijding van misverstand moge hier direct worden opgemerkt, dat deze qualificatie niet bedoelt iets denigrerends ten aanzien van de controleursfunctie in te houden. Bepaaldelijk wil niet gesuggereerd worden dat het controlevak gemakkelijk zou zijn omdat het "maar" toepassing van een techniek is. Deze toepassing is beslist wél moeilijk; ten eerste omdat het onderkennen van de categorie waartoe een probleem behoort in vele gevallen een scherp inzicht en een grote ervaring vereist, ten tweede omdat de techniek slechts door een langdurige studie zowel van een aantal aanrakingsvlakken als van de controleleer zelf eigen kan worden gemaakt;

- de administratieve deskundige en de adviseur passen hun gehele kennis van het gebied waarop zij werkzaam zijn toe op het hun voorgelegde geval. Hun waarde schuilt in de wijze waarop zij analyses kunnen maken van het concrete probleem en de wijze waarop zij hun reeds bekende oplossingen en deeloplossingen kunnen combineren tot een doelmatige (bij voorkeur de meest doelmatige) totaal-oplossing van het concrete probleem.

Het verschil in karakter tussen de controleursfunctie en de beide andere functies van de accountant heeft consequenties voor de opleiding en de beroepsuitoefening. Voor de opleiding betekent het dat de qualificatie "volslagen controleur" in principe bereikbaar is voor ieder die over voldoende intelligentie beschikt en voldoende verantwoordelijkheidsgevoel heeft; terwijl de beide andere functies meer of minder goed zullen kunnen worden aangeleerd, al naar mate de leerling meer of minder aanleg in de desbetreffende richting heeft.

Voor de beroepsuitoefening is de consequentie dat in principe elke accountant elke controle-opdracht op afdoende wijze moet kunnen uitvoeren, terwijl de kwaliteit van de uitvoering van opdrachten op het gebied van de administratieve organisatie en van adviesopdrachten, zal afhangen van de persoonlijke geschiktheid van de gekozen accountant voor het aan de orde gestelde onderwerp.

In het voorgaande is er stilzwijgend van uitgegaan dat het controlevak een ondeelbaar geheel vormt, dat er met name niet kan worden gesproken van een specialisatie daarbinnen naar bedrijfstak. Dit vraagstuk valt buiten het bestek van dit artikel; volstaan moge worden met een verwijzing naar de conclusie van Prof. Dr. H. J. v. d. Schroeff (M.A.B. 1947, blz. $284)$,„dat er heden ten dage geen openbaar accountants gevonden zullen worden, die specialisatie..... zouden willen voorstaan".

\section{De huidige functies van de openbare accountant in Nederland.}

De openbare accountantspraktijk wordt thans in Nederland in een aantal vormen uitgeoefend. Vanaf de alleenwerkende accountant met een 
aantal assistenten, opklimmend via de kleinere associaties tot de zeer grote associaties met een aantal in dienstverband werkende accountants,

De omstandigheid dat de controlewerkzaamheden doelmatig met hulp van assistenten kunnen worden verricht, verklaart grotendeels het ontstaan van associaties waarbij twee of meer volslagen controleurs hun praktijken tezamen brengen, teneinde de proportionaliteit in de assistenten en het overige hulppersoneel te verbeteren en zodoende tot een beter economisch resultaat te komen.

Deze omstandigheid verklaart echter niet de relatief zeer grote associaties, die veelal reeds lang de grens hebben overschreden waarop het effect van verbetering der proportionaliteit wordt tenietgedaan door de ex tra kosten als gevolg van de noodzaak steeds meer aandacht te besteden aan de coördinatie.

Een van de hoofdoorzaken van het ontstaan en voortbestaan van deze grote associaties moet dan ook worden gezocht in de functies van administratieve deskundige en van adviseur, waarbij tot nu toe de laatste de hoofdrol speelt. Immers de adviseursfunctie kan slechts bij uitzondering op alle gebieden doelmatig door de alleenwerkende accountant of de kleine associatie worden uitgeoefend. De geschiktheid van de geraadpleegde accountant voor het concrete probleem bepaalt in hoge mate de waarde van het advies. In de grote associatie bestaat de mogelijkheid het concrete probleem intern voor te leggen aan de associé of de in dienstverband werkzame accountant die het betrokken gebied het beste beheerst. Zelfs bestaat veelal de mogelijkheid intern nadere inlichtingen in te winnen bij een specialistisch geschoolde niet-accountant, die in dienst van de associatie is.

Resumerend kan dus gesteld worden dat "de" openbare accountant in Nederland (waaronder mede te verstaan de associatie) de functies uitoefent van:

a. onafhankelijke controleur, welke functie de kern van het beroep vormt en ook werkt tegenover derden-niet-opdrachtgevers;

b. adviseur van de leiders van bedrijfshuishoudingen ten aanzien van alle beslissingen met belangrijke economische gevolgen;

c. deskundige op het gebied der administratieve organisatie.

\section{Het adviseursschap.}

Het is nodig de adviesfunctie van de accountant, die in het voorgaande nog wat vaag en ongedifferentieerd is gebleven, nader te bezien.

Het bedrijfsleven kent zelfstandige, zowel als binnen de bedrijfshuishoudingen werkzame adviseurs op allerlei gebied. Sommigen van hen bekleden een ambtelijke functie (bv. Rijksnijverheidsconsulenten), zij geven hun adviezen gratis of tegen een geringe vergoeding; anderen zijn verbonden aan commerciële instellingen (bv. handelsbanken, verzekeringsinstellingen) die de adviezen bij wijze van service gratis aan hun relaties doorgeven; een derde groep vormen de interne staffunctionarissen; de laatste groep vormen de beofenaren van verscheidene vrije beroepen.

In dit beeld past de accountant als adviseur op het gebied van de administratieve organisatie en als belastingadviseur (zolang het vrije beroep van belastingdeskundige althans nog onvoldoende vorm heeft gekregen). Zo goed als van de eerder genoemde adviseurs, ieder op zijn gebied, mag van de accountant op deze terreinen een specialistische kennis worden verwacht. 
Het zal duidelijk zijn dat deze functie niet is bedoeld in het voorgaande waar sprake was van de adviseursfunctie van de accountant. De ervaring leert dat het bedrijfsleven behalve aan specialistische deskundigen op allerlei gebied (om maar enkele te noemen: architect, electro-technisch ingenieur, werktuigkundig ingenieur, commercieel adviseur, psychotechnicus, actuaris, geneeskundig adviseur enz.) behoefte heeft aan een algemene adviseur, met wie importante problemen nu eens in hun totaliteit synthetisch - kunnen worden besproken. Deze algemene adviseur dient in een onafhankelijke positie te staan, niemand naar de ogen te behoeven te zien, een uitgebreide ervaring in het bedrijfsleven te hebben en op grond van zijn opleiding en ervaring een gezonde kijk te hebben op allerlei problemen waarmee de tegenwoordige bedrijfsleider wordt geconfronteerd.

Deze vererende functie valt in vele gevallen toe aan de openbare accountant. Wij kunnen ons afvragen of de accountant wel de meest geschikte functionaris voor deze synthetiserende adviseursfunctie is. Deze vraag zou kunnen worden afgedaan met de mededeling dat het bedrijfsleven er zelf wel voor zal zorgen dat het de meest geschikte functionaris kiest, doch er zijn ook zelfstandige motieven voor de geschiktheid van de accountant voor deze functie aan te voeren:

- de voortgezette waarneming van de totaliteit van het bedrijfsgebeuren die de openbare accountant uit hoofde van $z$ ijn controlefunctie doet (vergelijk R. W. Starreveld in M.A.B. 1950, blz. 11);

- de ervaring over een breed vlak die de openbare accountant normaliter heeft;

- de opleiding van de accountant, die zich over verscheidene nevengebieden uitstrekt;

- het feit dat de accountant bij zijn opleiding heeft geleerd de bedrijfsproblemen vanuit een economisch gezichtspunt te bezien;

- de onafhankelijke positie die de openbare accountant reeds uit hoofde van zijn controlefunctie inneemt.

Door Prof. Dr. H. J. v. d. Schroeff is er (M.A.B. 1947, blz. 282 e.v.) de aandacht op gevestigd dat bij een samengaan van adviserende en controlerende functies in één persoon of één associatie, een collisie kan ontstaan die ten nadele van de controlefunctie komt.

Zonder uitvoerig in dit verband op het betoog van Prof. v. d. Schroeff in te gaan, moge hier tegen worden opgemerkt, dat een dergelijke collisie alleen mogelijk is indien de adviezen een overwegende invloed hebben op het bedrijfsonderdeel waarover geadviseerd wordt. $\mathrm{B}_{\mathrm{ij}}$ een juiste uitvoering van de adviserende taak en een juist gebruik van de verstrekte adviezen door de bedrijfsleiding, zal het altijd deze laatste zijn die de volle verantwoordelijkheid voor het bedrijfsgebeuren, al dan niet met inachtneming van het advies, behoudt. Het overschrijden van de praktisch gemakkelijk te bepalen grens, waarvoorbij de adviezen overgaan in beleidsbepaling, is niet slechts voor de controleur, doch voor elke adviseur ongewenst.

Het moge praktisch hier en daar voorkomen dat de adviezen van een controlerende accountant zodanig invloed hebben op het beleid, dat deze accountant een „,belang” krijgt bij een gunstige voorstelling van het resultaat van zijn advies, in principe is deze gang van zaken voor elke adviseur verwerpelijk. Immers bij een juiste opvatting van de adviseurstaak is er geen sprake van een resultaat van een advies, doch van een resul- 
taat van de opvolging en uitvoering van een advies, een opvolging en uitvoering die geheel en al tot de taak en de verantwoordelijkheid van de bedrijfsleiding behoren.

\section{De toekomstige ontwikkeling.}

Indien men spreekt over de toekomstige ontwikkeling van een beroep, kan men zich op twee standpunten stellen. Men kan nagaan welke ontwikkeling op grond van bestaande verhoudingen verwacht mag worden of men kan desiderata voor de toekomstige ontwikkeling stellen en daarbij aanstippen welke maatregelen zullen moeten worden getroffen om aan deze desiderata te voldoen. In het onderstaande zal het tweede standpunt worden ingenomen.

Onder beroepsgenoten bestaat ontegenzeggelijk de tendentie de controleursfunctie en de functie van deskundige op het gebied der administratieve organisatie voor de toekomst in het centrum te plaatsen. De adviserende werkzaamheden wil men afstoten, voorzover zij niet rechtstreeks tot deze beide functies behoren (zie bv. Prof. T. Keuzenkamp in M.A.B. 1949 , blz. 162 e.v.).

Uit de publicaties zou men kunnen afleiden dat deze tendentie zeer sterk is; de stemmen er tegen zijn immers incidenteel en vrij zwak. Blijkens beraadslagingen in de Eerste Kamer der Staten Generaal van enige jaren geleden trekt het maatschappelijk verkeer deze conclusie ook. In de praktijk ziet men echter wel anders.

De grote accountantskantoren treden in verscheidene gevallen ook op als belastingadviseurs, als algemene bedrijfseconomische adviseurs, als organisatie-adviseurs. Van de kleinere kantoren (tot en met drie accountants) mag worden aangenomen dat een groot deel van hun taak bestaat uit het geven van belasting - en bedrijfseconomische adviezen. Deze kleinere kantoren vormen volgens de statistiek van Drs. A. F. Reijn (M.A.B. 1952 blz. 223) bijna 90\% van het aantal vestigingen, waarbij ruim $50 \%$ van het aantal openbare accountants werkzaam is.

Deze accountants hebben bij een groot deel van hun relaties niet in de eerste plaats waarde als onafhankelijke controleurs, wier oordeel in het maatschappelijk verkeer wordt geaccepteerd. $Z_{i j}$ worden door hun cliënten vooral gewaardeerd als onafhankelijke adviseurs. Indien de verhouding tussen cliënt en accountant goed is - de zeer grote concerns buiten beschouwing gelaten — dan zal de cliënt vele beslissingen van importantie tevoren aan het oordeel van zijn accountant onderwerpen. Dit betekent niet dat de cliënt $\mathrm{nu}$ in zijn accountant de man ziet die bij uitstek deskundig is op al die gebieden waarop hij hem raadpleegt; de cliënt weet wel beter. Hij vertrouwt er echter op dat de accountant voldoende algemeen inzicht heeft om hem te adviseren een specialistische deskundige te raadplegen indien het probleem buiten zijn eigen scope of die van zijn associés en zijn personeel gaat en van voldoende belang is.

Alleen in deze omstandigheden is de verhouding opdrachtgever-accountant volkomen; alleen in deze omstandigheden is de accountant in de volle betekenis vertrouwensman, niet alleen voor het maatschappelijk verkeer, maar ook voor de opdrachtgever zelf.

Deze vertrouwenspositie is een teer plantje; één onvoldoende doordacht advies, één onzorgvuldige behandeling van zaken schaadt reeds ernstig in de groei. Een enkele herhaling doet de opdrachtgever zich terugtrekken; hij wendt zich tot andere adviseurs, in laatste instantie ook tot een andere 
controlerende accountant. Deze mislukkingen zijn uiteraard nimmer geheel te vermijden; zij slaan echter slechts terug op de individuele accountant, die bij zijn individuele relatie het vertrouwen heeft verspeeld.

Veel ernstiger is de zaak indien door verzuring van de bodem het leven van al deze plantjes onmogelijk wordt gemaakt, d.w.z. als de accountants zelf in hun publicaties - en straks misschien zelfs rechtstreeks tegenover hun opdrachtgevers - beweren dat zij als groep dit vertrouwen niet verdienen.

De aandacht moge er op worden gevestigd dat een vergelijkbare vertrouwenspositie nog niet zo heel lang geleden werd ingenomen door de notarissen. Het is geen toeval dat - in het bijzonder in de grote steden en uitzonderingen daargelaten - de notaris ten aanzien van het bedrijfsleven is teruggedrongen tot de positie van een akte-passerende ambtenaar, bij wie slechts particulieren ook om advies in algemene zin aankloppen. De notarissen als groep toch, hebben zich in de periode waarin de administratie van het bedrijfsgebeuren een steeds groter aandeel van de belangstelling der bedrijfsleiders ging opeisen, hiervan te enenmale gedistancieerd, en later, toen de belastingen op de voorgrond traden, hetzelfde gedaan ten aanzien van de behandeling van fiscale aangelegenheden.

Een soortgelijk lot is beschoren aan elke groep van algemene adviseurs-vertrouwenslieden, die zich distancieert van de problemen die in een gegeven tijdsbestek de aandacht van de bedrijven opeisen. Dit behoeft nauwelijks betoog, want welke zin heeft het voor een bedrijfsleider om zijn problemen met een algemeen adviseur te bespreken als deze niets zinvols kan of wil zeggen over dat wat in het centrum van de aandacht van de bedrijfsleider staat.

Dit betekent dat de accountant die zijn vertrouwenspositie wilde handhaven in de tijd van prijs- en deviezenvoorschriften, daarin een algemeen inzicht en daarvan een principiële kennis moest hebben.

Dit betekent thans dat de accountant die in de komende jaren zijn positie als vertrouwensman wil handhaven, een algemeen inzicht moet hebben in en een principiële kennis moet dragen van belastingaangelegenheden, die nog steeds een groot (doch verminderd) deel van de belangstelling opeisen, en van de methoden van productiviteitsverbetering, die zonder twijfel een steeds groter deel van de aandacht in de toekomst zullen verkrijgen.

Indien wij het toekomstige arbeidsterrein van de accountant uit deze gezichtshoek behandelen, krijgen wij - naar ondergetekende wil voorkomen - een zuiverder beeld en een nuchterder kijk, dan wanneer wij ons op het standpunt stellen: ,de huidige opleiding van de accountant is zo en zo, op grond daarvan kan hij die en die werkzaamheden aan, uitbreiding van de - toch al 10 jaar in beslag nemende - opleiding is onaanvaardbaar, dus over andere taken dan genoemde 'die en die werkzaamheden' mogen wij niet denken". Wij zullen dan beseffen dat een groepsgewijze distanciëring van actuele problemen de belangrijke adviseursfunctie in gevaar brengt en dat het veel meer de taak van de accountant als groep is middelen te beramen om te zorgen dat hun dienende taak ten behoeve van het bedrijfsleven zo goed mogelijk vervuld kan blijven, ook indien de omstandigheden zich wijzigen.

Middelen ter bereiking van het gestelde doel:

Ter bereiking van het hiervóór gestelde doel - handhaving van de vertrouwenspositie van de accountant bij wijzigende omstandigheden — wor- 
den onderstaande, zeer globaal besproken middelen gezien. Hierbij staat voorop dat de accountant onder alle omstandigheden een volslagen controleur moet blijven. Aangezien deze kern van het beroep tevens een belangrijk asset vormt bij hetgeen de accountant ter uitoefening van zijn adviseursfunctie nodig heeft, is deze vooropstelling ten volle in overeenstemming met het doel.

\section{A. De praktijkuitoefening.}

De aanpassing aan de wijzigende omstandigheden kan in de eerste plaats in de uitoefening van de praktijk worden bereikt, door associaties van accountants met verschillende mate van aanleg voor verschillende onderdelen van de adviserende functie. Allen zullen zich bij voorkeur ook in feite met de controlepraktijk moeten belasten, daar zij slechts hierdoor de noodzakelijke voeling met hetgeen in het bedrijfsleven groeit kunnen behouden.

Intern kan een verbijzondering worden verwacht, waarbij in de eerste plaats de praktische ervaring en aanleg en pas later de opleiding, een rol spelen.

Intern kan verder worden verwacht een verbijzondering van het personeel, waarbij echter in aanmerking dient te worden genomen dat die personeelsleden die vermoedelijk hun accountantsstudie zullen volbrengen, niet prematuur als specialist in een of andere richting worden geclasseerd.

\section{B. De opleiding.}

Tot nu toe heeft de opleiding zich aan de groeiende eisen van de prak. tijk aangepast door geregelde uitbreiding, in beperkte mate in de breedte (de vakken), in sterke mate in de diepte (de eisen per vak te stellen).

De uitbreiding van de opleiding is aan een grens gebonden; onder de huidige omstandigheden is deze grens bereikt of wellicht reeds overschreden. Niettemin breidt het gebied waarop het bedrijfsleven behoefte heeft aan niet-specialistische, synthetische adviezen, zich verder uit. Wil de opleiding zich aan deze behoefte aampassen - in het voorgaande is betoogd dat een dergelijke aanpassing een levensvoorwaarde is - dan zal verdere uitbreiding in de breedte noodzakelijk zijn.

Dit betekent echter gelijktijdig een beperking in de diepte, van een aantal vakken omdat immers de grens van de duur der opleiding bereikt wordt geacht.

Hoe deze beperking in de diepte ook wordt gerealiseerd, zij zal de grondslag dat elke accountant een volslagen controleur moet zijn nimmer mogen aantasten. De beperking dient daarom slechts betrekking te hebben op die vakken die voor de adviseursfunctie in het bijzonder hun betekenis hebben. Het is een gunstige omstandigheid (overigens geen toevallige) dat dit dezelfde vakken zijn waarvoor de individuële aanleg een belangrijke rol speelt.

Hierdoor is het namelijk mogelijk naast de basis-opleiding die voert tot een volslagen controleurspositie, keuze-richtingen in te stellen waaruit elke studerende één of meer dient te kiezen. Deze keuze kan dan worden gedaan op grond van de persoonlijke aanleg en ambitie. De keuze-richting verdiept de opleiding op het gekozen terrein, zodat de accountant op dat terrein een meer-specialistische kennis bezit dan zijn collega's van een andere keuze-richting.

Door het instellen van de keuze-richtingen kan in de diepte van de ba- 
sis-opleiding een belangrijke beperking worden aangebracht. (Om een voorbeeld te noemen: de controlerende accountant behoeft slechts in zoverre het terrein der administratieve organisatie te beheersen als voor een goed begrip van de controleleer nodig of gewenst is; met name vaardigheid in de toepassing van administratieve technieken behoeft van hem niet te worden geëist). Deze beperking in de diepte kan verder leiden tot een thans geringe, later wellicht wederom groeiende uitbreiding in de breedte.

Men kan zich afvragen of een dergelijke wijziging bezwaren zou oproepen ten aanzien van de status van het accountantsberoep en met name of de verworven gelijkstelling van academisch gevormde en particulier opgeleide accountants in gevaar gebracht zou kunnen worden. Dit gevaar lijkt bepaald niet groot, mits de basis-opleiding leidt tot een volslagen con troleursschap. Ook thans immers geldt de gelijkstelling van academisch gevormde en elders opgeleide accountants slechts ten aanzien van het con troleursschap (en in zekere mate ten aanzien van de deskundigheid op het terrein van de administratieve organisatie). Zolang de academische accountantsopleiding gehandhaafd wordt als post-doctorale studie van de economische hogescholen en faculteiten, is de elders opgeleide accountant op economisch terrein niet gelijkwaardig aan de academicus.

Zelfs kan de wijziging het tegenovergestelde effect hebben, omdat de accountant (niet-academicus), die de economische richting heeft gekozen, een opleiding kan ontvangen die geheel op academisch niveau ligt. Hoewel hij dan wellicht op andere wijze in vorming bij de academicus ten achter blijft staan, kan hij althans qua verworven kennis in alle opzichten gelijkwaardig zijn.

Er zijn andere belangrijke voordelen. Hoewel de Nederlandse accountants zich mede aandienen als deskundigen op het gebied der administratieve organisatie, is de opleiding bepaald niet adequaat aan de uit dit epitheton voortvloeiende eisen: problemen van doelmatige werkwijze en doelmatige taakverdeling, vraagstukken van mechanisatie, van de schrijfmachines met voorsteekinrichting, via de regeldrukkende vloeistofduplicators, de klassieke boekhoudmachines en de ponskaarteninstallaties tot de moderne computers en pons- of magnetische bandapparatuur komen slechts uiterst summier in de opleiding aan de orde. De betrekkelijk weinige Nederlandse accountants van wie gezegd kan worden dat zij deskundig op dit terrein zijn, hebben deze deskundigheid buiten de opleiding en de examens verworven. Instelling van een keuze-richting administratieve organisatie opent de mogelijkheid voor degenen die daartoe de aanleg bezitten in hun opleiding een werkelijke deskundigheid op dit terrein te verwerven.

Er zijn meer hiaten in de aanpassing van de opleiding aan de praktische eisen; het komt niet noodzakelijk voor deze in den brede op te sommen; zolang door beperking elders geen "ruimte" in de opleiding is gevonden, moeten ze noodgedwongen worden geaccepteerd.

\section{Voorbeeld.}

Ter illustratie moge hieronder een voorbeeld worden gegeven van de wijze waarop de opleiding zou kunnen worden georganiseerd:

1. Basis-opleiding.

I Voorbereidend.

A. Techniek van de handel. Ongewijzigd. 
BI. Financiële rekenkunde. Geen eis van vaardigheid in de toepassing, uitsluitend inzicht in de onderwerpen.

BII. Levensverzekeringswiskunde. Kan geheel vervallen.

BIII. Statistiek. Wel inzicht, geen vaardigheid in de toepassing.

C. Voortgezet boekhouden. Uitgebreid met kennis van de wettelijke voorschriften, zowel die in het algemeen als die slechts voor bepaalde bedrijfstakken gelden.

D. Recht. Uitgebreid met kennis van de opbouw en bevoegdheden der publiek-rechtelijke bedrijfsorganisatie en van de administratieve rechtspraak voorzover het bedrijfsleven rakende (loonbeheersing, prijsbeheersing, vormen van fiscale rechtspraak).

E. Belastingrecht. Uitgebreid met kennis van de sociale verzekeringswetgeving gezien vanuit het standpunt van het bedrijf.

II Economisch.

A. Sociale economie. Belangrijke beperking ten aanzien van het geld-, krediet- en bankwezen.

B. Bedrijfshuishoudkunde. Belangrijke beperking ten aanzien van de leer van de organisatie.

III Accountancy.

A. Inrichtingsleer. Beperkt tot: Inzicht in de algemene beginselen van de leer der administratieve organisatie en kennis van de administratieve organisatie van huishoudingen van verschillende aard, voorzover deze onmisbaar is voor een goede toepassing van de controleleer.

B. Controleleer. Ongewijzigd.

IV Slotexamen. Vervalt in de basis-opleiding, dient een onderdeel van de keuze-opleiding te vormen.

2. Keuze-richtingen.

I Bedrijfseconomische richting: aanvullende studie sociale economie en bedrijfshuishoudkunde tot academisch niveau.

II Belastingrichting: aanvullende studie recht en gedetailleerde studie Nederlands belastingrecht; hoofdzaken van de belastingheffing in enkele andere landen waarmede door Nederlandse ondernemingen nauwe economische betrekkingen worden onderhouden.

III Richting administratieve organisatie: aanvullende studie Inrichtingsleer; uitgebreide studie technische hulpmiddelen; vaardigheid in de toepassing.

IV Algemeen organisatorische richting: aanvullende studie bedrijfshuishoudkunde (leer van de organisatie), wiskunde (operations research en statistiek) en vaardigheid in de toepassing.

$\mathrm{V}$ Financieel-economische richting: vaardigheid in de toepassing van de onderwerpen der financiële rekenkunde; grondslagen der levensverzekeringswiskunde; aanvullende studie statistiek; algemene beginselen geld-, krediet- en bankwezen; aanvullende studie bedrijfshuishoudkunde (leer van de financiering). 
Bij wijziging van omstandigheden laten de keuze-richtingen zich gemakkelijk aanpassen, zonder dat de basis-opleiding behoeft te worden verzwaard.

\section{Samenvatting.}

De openbare accountant in Nederland vervult een drietal functies, t.w. de controlerende functie, de functie van administratieve deskundige en de adviseursfunctie. De eerste functie vormt de kern van het beroep; zij is door ieder met voldoende intelligentie, verantwoordelijkheidsbesef en opleiding in principe even goed uit te oefenen. De beide andere functies hebben een ander karakter, de kwaliteit van de in deze functies verrichte werkzaamheden hangt sterk af van de individuële aanleg. Van de drie functies is de adviseursfunctie een zeer belangrijke in de praktische beroepsuitoefening.

De verschillende geschiktheid van individuële accountants voor verschillende onderdelen van de adviseursfunctie leidt tot associaties van accountants.

De adviseursfunctie van de accountant is niet een functie van een specialistische deskundige, doch die van een algemene bedrijfsdeskundige, met wie problemen in hun totaliteit kunnen worden besproken. Er zijn verschillende motieven voor de geschiktheid van de accountant qua ervaring en opleiding voor deze algemene adviseursfunctie. Bij een juiste taakopvatting van de adviseur zal er geen collisie ontstaan met zijn controlerende functie.

Publicaties der laatste jaren wekken de indruk dat de accountants van hun adviseursfunctie willen worden ontheven. Dit is echter niet in overeenstemming met de ontwikkeling in de praktijk.

De adviseursfunctie kan voor de accountants slechts behouden blijven indien zij zich aanpassen aan zich wijzigende omstandigheden, zodat de bedrijfsleider zijn actuële problemen doelmatig met hen kan bespreken. De middelen om tot deze aanpassing te geraken zijn gelegen in de praktijkuitoefening en in de opleiding. Voor de praktijkuitoefening wordt het vormen van associaties van accountants met verschillende aanleg en voor de opleiding wordt het instellen van keuze-richtingen naast de basis-opleiding tot volslagen controleur, als mogelijkheden tot aanpassing gezien.

\section{Summary}

The public accountant in the Netherlands fulfils three functions, i.e. the audit function, the function of an expert on accounting and recordkeeping and the consulting function. The first function is the nucleus of the profession, in principle it can be practised by anyone with sufficient intelligence, sense of responsibility and training. The other two functions have an entirely different character, the quality of the achievements in this function depend largely on the individual capacities. Of the three functions the consulting function is the most important in the practical exercise of the profession.

The different aptitude of individual accountants for different aspects of the consulting function leads to associations of accountants. 
The consulting function of the accountant is not a function of a specialized expert, but that of a general business expert, with whom problems can be discussed in their totality. There are several reasons for the aptitude of the accountant for this general consulting function as regards experience and training. If the task is conceived by the consultant in the right way, there will be no collision with his audit function.

Publications in the last few years give the impression that the accountants would wish to be relieved from their consulting function. This, however, is not in accordance with the actual development in practice.

The consulting function can only be retained by the accountants if they adapt themselves to the changed circumstances, so that the manager can adequately discuss his problems of the moment with him. The means to arrive at this adaptation are to be found in the exercise of the profession and in the training. As regards the exercise of the profession the formation of associations of accountants with different capacities and as regards the training the establishment of optional subjects by the side of the basic training for qualification as an auditor are considered to be possibilities of adaptation.

\section{Résumé}

Aux Pays-Bas l'expert-comptable remplit trois fonctions: celles de contrôleur (réviseur), d'expert administratif et de conseiller. La première de ces fonctions constitue le pivot de sa profession: elle peut être remplie en principe par toute personne ayant des aptitudes suffisantes, sens des responsabilités et une formation technique adéquate. Les deux autres fonctions ont un caractère tout différent: la qualité des travaux exécutés dans le cadre de ces fonctions dépend, dans une grande mesure, des dispositions individuelles. Dans la pratique professionnelle la fonction de conseiller est sans doute la plus importante.

Leurs aptitudes particulières pour les différents aspects de la fonction de conseiller incitent les experts-comptables à s'associer entre eux.

La fonction de conseiller n'est pas celle d'un expert spécialisé, mais d'un expert .général" avec qui les problèmes peuvent être étudiés dans toute leur ampleur. Il y a plusieurs causes qui rendent l'expert-comptable, quant à son expérience et à sa formation, apte à remplir cette fonction de conseiller général. Lorsque l'expert-comptable se fait une conception exacte de la fonction de conseiller, aucune confusion ne saurait se présenter avec sa mission de contrôleur.

Il se dégage dans la littérature de ces dernières années une tendance selon laquelle les experts-comptables aimeraient être déchargés de la fonction de conseiller. Ce désir est cependant contraire à l'évolution que montre la pratique.

Les experts-comptables ne peuvent en effet conserver la fonction de conseiller que s'ils s'adaptent constamment aux changements qui surviennent dans l'économique, de sorte que le chef d'enterprise puisse discuter efficacement avec eux ses problèmes actuels. Les moyens pour arriver à cette adaptation sont l'expérience professionnelle et la formation technique.

L'auteur conclut que des associations entre des experts-comptables ayant des aptitudes différentes permettra de parvenir à cette adaptation dans la pratique professionnelle tandis que, en ce qui concerne la formation technique la création de matières à option à côté de la formation complète de base de contrôleur est également susceptible d'atteindre le but désiré. 